DOI: 10.24867/MD.9.2017.2.45-50

Research paper

\title{
LOAD CAPACITY OF CYLINDRICAL WORM GEARS ACCORDING TO DIN 3996-2012
}

\author{
Aleksandar MILTENOVIĆc, ${ }^{*}$ - Milan BANIĆ ${ }^{-}$- Đorde MILTENOVIĆ 2 \\ 1 University of Niš, Faculty of Mechanical Engineering, Niš, Serbia \\ 2 High Technical and Textile School, Leskovac, Serbia
}

Received (26.05.2016); Revised (14.09.2016); Accepted (19.09.2016)

\begin{abstract}
A worm drive is widely used in power and movement transmission, and the proper functioning of the entire machine system depends on it. The advantages of a worm drive, compared to other types of drives, are primarily reflected in its compact design, large transmission ratio, reliability, the possibility of vibration damping, as well as in structural advantages regarding branching and summarising energy, etc. Its capacity is limited by the emergence of a larger number of boundary conditions when in exploitation. This paper considers load capacity calculations of worm gears according to DIN 3996-2012.
\end{abstract}

Key words: worm gear, load capacity, DIN 3996.

\section{INTRODUCTION}

Worm gears are widely used in tool machines, transport equipment, in vehicles, primarily for power transmission, as well as in fine-tuning and precision devices for movement transmission.

Worm pairs load capacity is nowadays based on the DIN 3996 [1], which was introduced with dimensionless physical parameters, pressure parameter $p_{m}{ }^{*}$, oil film thickness parameter $h^{*}$ and mean slip path parameter $s^{*}$. Current information regarding the load capacity of worm pairs use the median surface pressure on flank $\sigma_{\text {Hlim }}$ of the output torque $T_{2}$ as authoritative criteria for the calculation of the flank load capacity. A prerequisite for a correct estimation of worm gear flanks load capacity regards to wear is the accurate knowledge of local flank teeth strain in different coupling conditions.

In the case of worm gear drive the absence of flank teeth wear has almost never been recorded. Research studies [2] show that worm pairs mostly operate under conditions of mixed friction. This indicates that tooth flank wear is not determined according to the hydrodynamic lubrication theory, but according to Hertz's theory, i.e it depends on the ratio between the radius curviture and the characteristics of the materials in contact.

The research in papers [4], [5] and [6] shows that surface pressure and temperature changes in the contact zone of coupled pairs have a major impact on worm gear wear.

\section{BOUNDARY CONDITIONS OF WORM GEARS}

In modern construction solutions it is common to use worm gears made of tin bronze and worms made of hardened and whetted steel (Fig. 1). Worm gears are affected by the following boundary conditions:

- Destruction of tooth flanks under pitting,

A tooth flank wear,
- Tooth breakage,

- Worming, mining and changing thermal stability of gear transmission,

- Worm shaft bending.

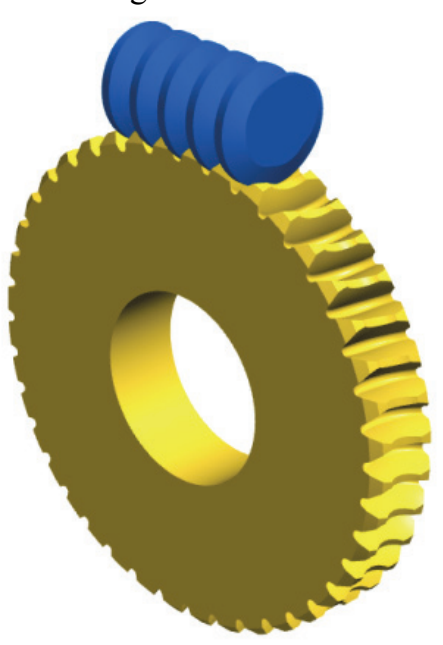

Fig. 1. Standard worm gear

\subsection{Pitting Resistance}

Pitting is, in effect, the destruction of a tooth surface (shaped like small holes and dimples) as a result of huge surface pressures and dynamic stress wear.

One can observe the difference between the initial and advanced stages of pitting. The initial stage of pitting is the result of the first phase of gears' transmission. It has a positive effect because it results in a uniform stress distribution and a better contact pattern. When working conditions are unchanged, this type of pitting decreases over time, i.e. the damaging process is digressive. Medium and highly loaded worm gear pairs can be affected by advanced pitting and this constitutes a huge problem. This sort of pitting has a progressive character, so much so that destroyed surfaces are larger while at the same time the contact pattern is smaller. Consequently, the damaged surface keeps expanding continuously and

*Correspondence Author's Address: University of Niš, Faculty of Mechanical Engineering, Aleksandra Medvedeva 14,

18000 Niš, Serbia, amiltenovic@yahoo.com 
changes in the shape of tooth surface occur. This results in a sudden tooth surface wear, and finally in a tooth breakage.

According to the DIN 3996 [1], the ratio between the limit value of contact stress $\sigma_{H k r}$ and mean contact stress $\sigma_{H m}$ represents a pitting safety:

$S_{H}=\frac{\sigma_{H k r}}{\sigma_{H m}} \geq S_{H \text { min }}=1$

\subsection{Wear Load Capacity}

During the period of mining wear, the continual tooth material wear width is smaller. In the first phase, the wear has a positive effect because one material rubs against another, thus allowing shapes of tooth surfaces to accommodate and consequently prevent any further wear. However, in the cases of high intensity rubbing, the wear resistance can be a criterion for a working period. The wear basically depends on working criteria. Changing shaft rotation conditions and the working mode, as well as terming the transmission gear on and off, result in increased wear. By using hard and quality worm tooth flanks (case carburising, whetting, polishing) one can reduce wear.

According to the DIN 3996 [1], the wear safety $S_{W}$ is calculated on the basis of the permissible wear $\delta_{\text {Wimn }}$ and abrasive wear in the normal section $\delta_{W n}$, according to the following equation (2).

$S_{W}=\frac{\delta_{W \lim n}}{\delta_{W n}} \geq S_{W \lim }=1,1$

\subsection{Root Strength of Teeth}

Worm gear pairs have dangerous working loads only in worm gear tooth root, considering that they are less resistant and less durable in comparison to worm teeth. In the worm gear tooth root there is a complicated load, and the dominant stresses are shear and bending.

Worm gear tooth breakage is very rare. The most common causes lie in striking overloads, when loads appear larger than the static strength of the material. The wear is also a significant cause of tooth breakage, since wear diminishes its cross-section.

According to the DIN 3996 [1], the safety of the teeth root strength $S_{\mathrm{F}}$ is calculated according to the following equation (3):

$S_{F}=\frac{\tau_{F k r}}{\tau_{F}} \geq S_{F \lim }=1,1$

where:

$\tau_{F \mathrm{kr}}$ - permissible shear stress,

$\tau_{F}$ - shear stress.

\subsection{Thermal Stability}

When designing a gearbox, one should also consider the heat generated inside the gearbox (efficiency of gearing, friction of bearings, and friction in sealing). This parameter is not so important in spur or bevel gearing, but it is in worm gearing. As worm gearing efficiency is considerably lower than that of spur or bevel gearing, far more heat is generated in the gearing process and has to be removed. Therefore, thermal safety has great importance for a correct design, to ensure gearbox function within the permitted temperature range of oil. Thermal design/safety tends to be one of the limiting factors when designing transmissions.

According to the DIN 3996 [1], thermal safety $S_{\mathrm{T}}$ is calculated according to the following equation (4):

$S_{F}=\frac{\vartheta_{S \lim }}{\vartheta_{S}} \geq S_{S \lim }=1,1$

where

$\vartheta_{\text {Slim }}$ - limit value of oil temperature

$\vartheta_{S}-$ oil temperature

\subsection{Worm Shaft Deflection}

A worm shaft is loaded by radial, axial and tangential force, which leads to considerable bending of the shaft, considering the relatively large distance between bearings. The shaft deflects due to bending which can lead to contact interference. The tangential force depends on friction against the teeth flanks. Thus, in the event of insufficient lubricating, the friction force increases, which results in a considerable deflection of a worm shaft. When loads and revolutions per minute change, the contact between tooth flanks decreases, as well as the local overload of the aforementioned. This can also result in a deflection of a worm shaft.

Monitoring of the work correctness is based on a control of the contact line between a tooth surface and on a control of a transmission gear thermal stability.

According to the DIN 3996 [1], a worm deflection safety $S_{\mathrm{F}}$ is calculated according to the following equation (5):

$S_{\delta}=\frac{\delta_{\lim }}{\delta_{m}} \geq S_{\delta \text { min }}=1$

where:

$\delta_{m}-$ a worm shaft deflection,

$\delta_{\text {lim }}$ - a permissible worm shaft deflection.

\section{LOAD CAPACITY OF WORM GEARS ACCORDING TO DIN 3996/2012}

An analysis of a worm gear load capacity is made for the family of gear drives with the characteristics given in Table 1. The calculation of a worm gear load capacity according to the DIN 3996 [1] has been performed on the basis of 4 criteria:

- Pitting resistance,

- Wear load capacity,

- Root strength of teeth and

- Thermal stability.

For the purposes of a comprehensive observation of worm gears load capacity according to different criteria, the following parameters were varied:

- Centre distance ( $a=63 \mathrm{~mm} ; a=100 \mathrm{~mm} ; a=250 \mathrm{~mm})$

- Transmission ratio $(i=10 ; i=20 ; i=30 ; i=40)$

- Input speed $\left(n_{l}=200 \mathrm{~min}^{-1} ; n_{l}=500 \mathrm{~min}^{-1}\right.$; $\left.n_{l}=1000 \mathrm{~min}^{-1} ; n_{l}=1500 \mathrm{~min}^{-1} ; n_{l}=2000 \mathrm{~min}^{-1}\right)$;

- Wheel material (CuSn12-C-GZ; CuAl10Fe5Ni5-CGZ; EN-GJS-400-15);

- Oil (mineral, synthetic);

- Lubrication (splash, injection). 
Aleksandar Miltenović, Milan Banić, Đorđe Miltenović: Load Capacity of Cylindrical Worm Gears According to DIN 3996-2012; Machine Design, Vol.9(2017) No.2, ISSN 1821-1259, E-ISSN 2406-0666; pp. 45-50
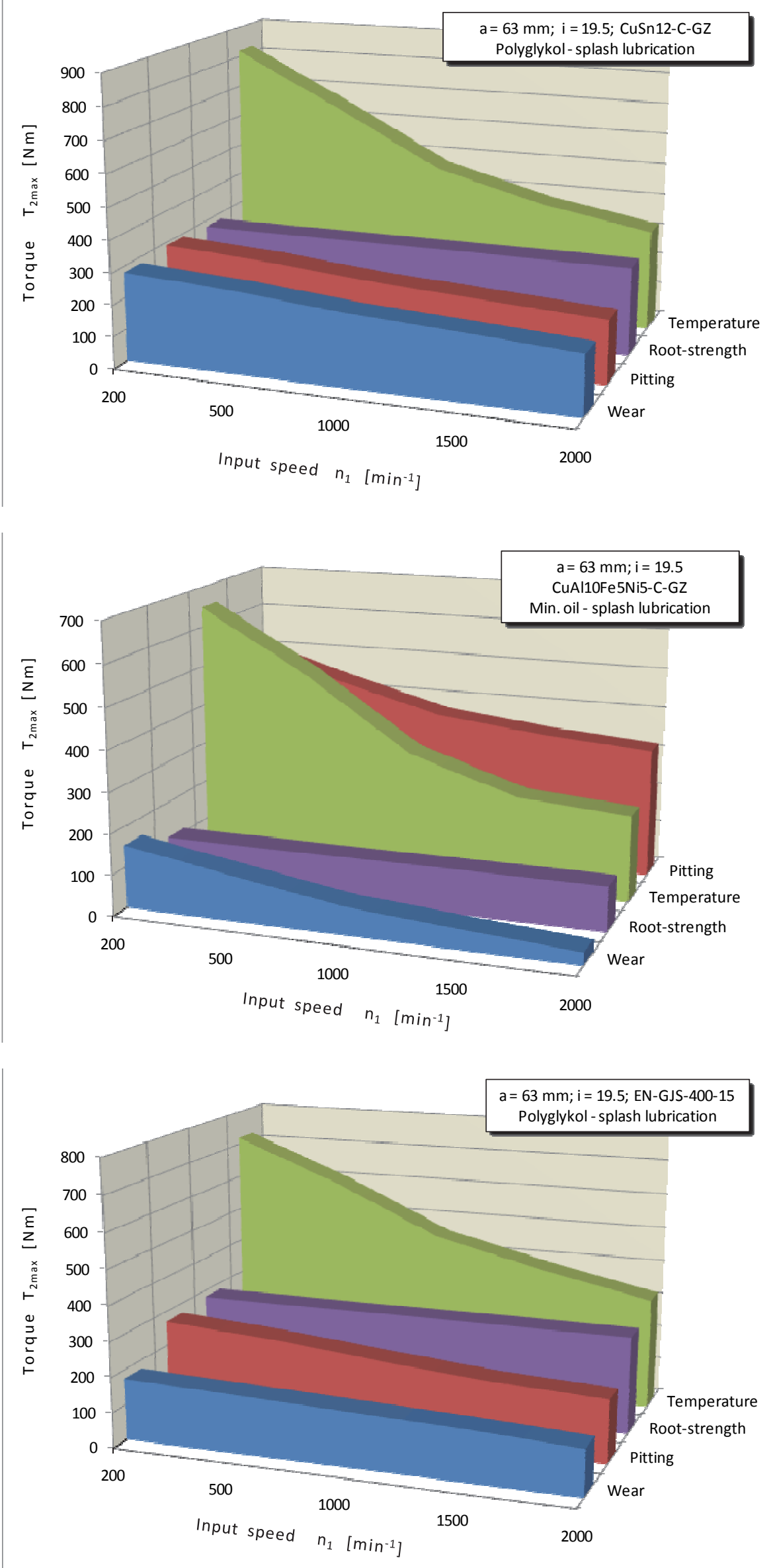

Fig.2. Comparison of worm gear load capacity for different values of input speed $n_{1}$ and different materials of the worm gear 

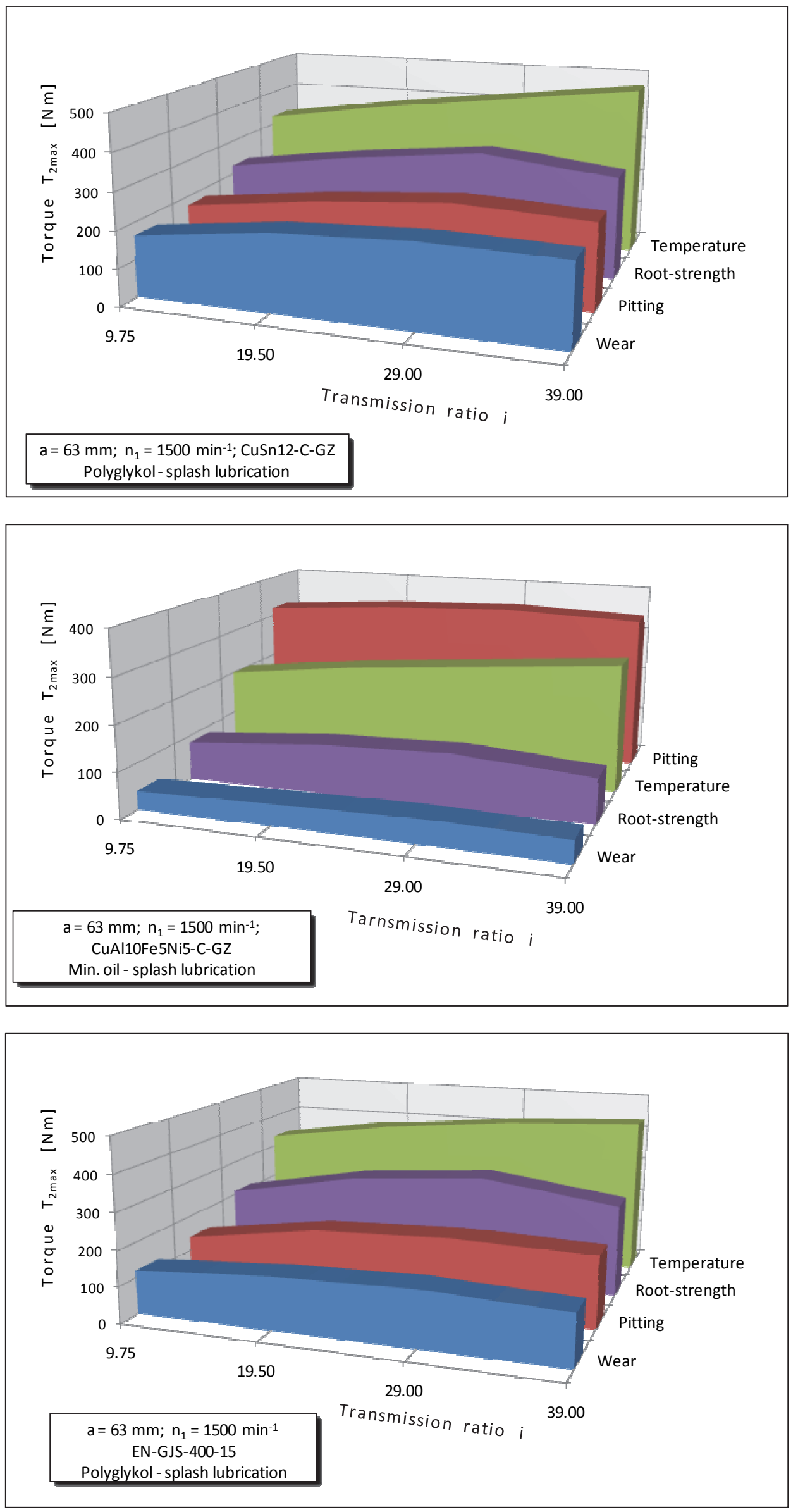

Fig.3. Comparison of worm gear load capacity for different values of transmission ratio $i$ and different materials of the worm gear 
Aleksandar Miltenović, Milan Banić, Đorđe Miltenović: Load Capacity of Cylindrical Worm Gears According to DIN 3996-2012; Machine Design, Vol.9(2017) No.2, ISSN 1821-1259, E-ISSN 2406-0666; pp. 45-50

Table 1. Transmission gear data

\begin{tabular}{|c|c|}
\hline Geometrical size & Values \\
\hline $\begin{array}{l}\text { Centre distance } a \\
{[\mathrm{~mm}]}\end{array}$ & $63,100,250$ \\
\hline Worm gears type & $\mathrm{ZI}$ \\
\hline Transmission ratio $i$ & $10,20,30,40$ \\
\hline Modul $m_{x}[\mathrm{~mm}]$ & $2.5,3.15,4,5,10,12.5$ \\
\hline Lifetime $L_{h}[\mathrm{~h}]$ & 10000 \\
\hline Number of teeth $z_{1}$ & $1,2,3,4$ \\
\hline Number of teeth $z_{2}$ & $20,30,40$ \\
\hline Wheel material & $\begin{array}{c}\text { CuSn12-C-GZ; } \\
\text { CuAl10Fe5Ni5-C-GZ; EN- } \\
\text { GJS-400-15 }\end{array}$ \\
\hline Worm material & $16 \mathrm{MnCr} 5$ \\
\hline Input speed $\left[\mathrm{min}^{-1}\right]$ & $200,500,1000,1500,2000$ \\
\hline $\begin{array}{l}\text { Synthetic oil } \\
\text { (Polyglykol) }\end{array}$ & $\begin{array}{l}v_{40}=220 \mathrm{~mm}^{2} / \mathrm{s} \\
v_{100}=41 \mathrm{~mm}^{2} / \mathrm{s}\end{array}$ \\
\hline Mineral oil & $\begin{aligned} v_{40} & =674 \mathrm{~mm}^{2} / \mathrm{s} \\
v_{100} & =36.9 \mathrm{~mm}^{2} / \mathrm{s}\end{aligned}$ \\
\hline
\end{tabular}

The critical thickness of the weared layer has been determined according to parietal thickness of top of the weared layer.

For each calculation the maximum output torque $T_{2 \max }$ was obtained for the required safety. The calculation results of the load capacity for centre distance $a=63 \mathrm{~mm}$ and different materials of the worm gear are shown in Figures 2 and 3. Similar diagrams have also been made for the centre distance $a=100 \mathrm{~mm}$ and $a=250 \mathrm{~mm}$.

Bearing in mind the variation of transmission ratio, speed, worm gears material and centre distance, the analysis required the calculation of 81 gear pairs.

The gear characteristics which are most widely used in practice have been chosen. The boundary condition of a gear is determined by the smallest load capacity. The results of the analysis have been presented in Table 2 . Figure 4 presents the results of the analysis by means of a column chart diagram. The diagram shows that the largest worm gear load capacity limitations are related to worm pair flank wear. (45). The second column represents pitting related limitations (36), and the third column represents thermal stability related limitations (18).

One should, however, bear in mind the interconnection between various forms of damage, first and foremost between wear and pitting [7]. Accordingly, the increase in load capacity in comparison to wear significantly affects the load capacity of the entire transmission gear. The same observation applies to thermal stability of transmission gears.
Table 2. Boundary conditions of worm gears

\begin{tabular}{|c|c|c|c|c|c|c|}
\hline \multirow{2}{*}{ No } & \multirow{2}{*}{$\begin{array}{l}\text { Wheel } \\
\text { mater. }\end{array}$} & \multirow{2}{*}{$i$} & \multirow{2}{*}{$\begin{array}{c}n \\
{\left[\mathrm{~min}^{-1}\right]}\end{array}$} & \multicolumn{3}{|c|}{ Centre distance $a[\mathrm{~mm}]$} \\
\hline & & & & 63 & 100 & 250 \\
\hline 1. & \multirow{9}{*}{$\begin{array}{l}0 \\
N \\
0 \\
0 \\
\vdots \\
\Xi \\
\Xi\end{array}$} & 10 & & \multirow{4}{*}{$\begin{array}{c}\mathbf{W}(\mathbf{P}) \\
\text { UN }\end{array}$} & \multirow{4}{*}{$\begin{array}{c}\mathbf{P} \\
\mathrm{UN}\end{array}$} & \multirow{3}{*}{$\mathbf{T}, \mathbf{P}, \mathrm{NUN}$} \\
\hline 2. & & 20 & & & & \\
\hline \multirow{2}{*}{4.} & & 30 & & & & \\
\hline & & 40 & & & & P, NUN \\
\hline 5. & & & 200 & \multirow{5}{*}{$\begin{array}{c}\mathbf{W}, \mathbf{P} \\
\mathrm{UN}\end{array}$} & \multirow{2}{*}{$\begin{array}{c}\text { W } \\
\text { UN }\end{array}$} & \multirow{3}{*}{$\mathbf{P}, \mathrm{NUN}$} \\
\hline 6. & & & 500 & & & \\
\hline 7. & & & 1000 & & \multirow{3}{*}{$\begin{array}{c}\mathbf{P} \\
\mathrm{UN}\end{array}$} & \\
\hline 8. & & & 1500 & & & \multirow{2}{*}{$\mathbf{T}, \mathrm{NUN}$} \\
\hline 9. & & & 2000 & & & \\
\hline 10. & \multirow{9}{*}{ 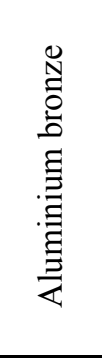 } & 10 & & \multirow{4}{*}{$\begin{array}{c}\mathbf{W} \\
\text { NUN }\end{array}$} & \multirow{4}{*}{$\begin{array}{c}\mathbf{W} \\
\text { NUN }\end{array}$} & \multirow{4}{*}{$\begin{array}{l}\mathbf{T}, \mathbf{W}, \\
\text { NUN }\end{array}$} \\
\hline 11. & & 20 & & & & \\
\hline 12. & & 30 & & & & \\
\hline 13. & & 40 & & & & \\
\hline 14. & & & 200 & \multirow{2}{*}{$\begin{array}{c}\mathbf{R} \\
\text { NUN } \\
\end{array}$} & \multirow{2}{*}{$\begin{array}{c}\mathbf{R} \\
\text { NUN } \\
\end{array}$} & $\mathbf{R}$, NUN \\
\hline 15. & & & 500 & & & \multirow{2}{*}{ W, NUN } \\
\hline 16. & & & 1000 & \multirow{3}{*}{$\begin{array}{c}\text { W } \\
\text { NUN }\end{array}$} & \multirow{3}{*}{$\begin{array}{c}\text { W } \\
\text { NUN }\end{array}$} & \\
\hline 17. & & & 1500 & & & $\mathbf{W}, \mathbf{T}, \mathrm{NUN}$ \\
\hline 18. & & & 2000 & & & T, NUN \\
\hline 19. & \multirow{9}{*}{ 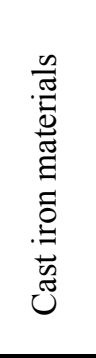 } & 10 & & \multirow{4}{*}{$\begin{array}{c}\mathbf{W} \\
\approx \mathrm{UN}\end{array}$} & \multirow{4}{*}{$\begin{array}{l}\mathbf{P}, \mathbf{W} \\
\approx \mathrm{UN}\end{array}$} & \multirow{4}{*}{$\mathbf{T}, \mathbf{P}, \mathrm{NUN}$} \\
\hline 20. & & 20 & & & & \\
\hline 21. & & 30 & & & & \\
\hline 22. & & 40 & & & & \\
\hline 23. & & & 200 & \multirow{5}{*}{$\begin{array}{l}\text { W } \\
\text { UN }\end{array}$} & \multirow{5}{*}{$\begin{array}{l}\mathbf{P}, \mathbf{W} \\
\approx \mathrm{UN}\end{array}$} & \multirow{3}{*}{$\mathbf{P}, \mathrm{NUN}$} \\
\hline 24. & & & 500 & & & \\
\hline 25. & & & 1000 & & & \\
\hline 26. & & & 1500 & & & $\mathbf{P}, \mathbf{T}, \mathrm{NUN}$ \\
\hline 27. & & & 2000 & & & $\mathbf{T}, \mathrm{NUN}$ \\
\hline $\begin{array}{l}\mathbf{W}-\mathrm{v} \\
\mathbf{T}-\text { th } \\
\text { NUN }\end{array}$ & & & ing (36 & $; \mathbf{R}-$ ro & $\begin{array}{c}\text { streng } \\
\text { load }\end{array}$ & $\begin{array}{l}(5) ; \\
\text { acity; }\end{array}$ \\
\hline
\end{tabular}

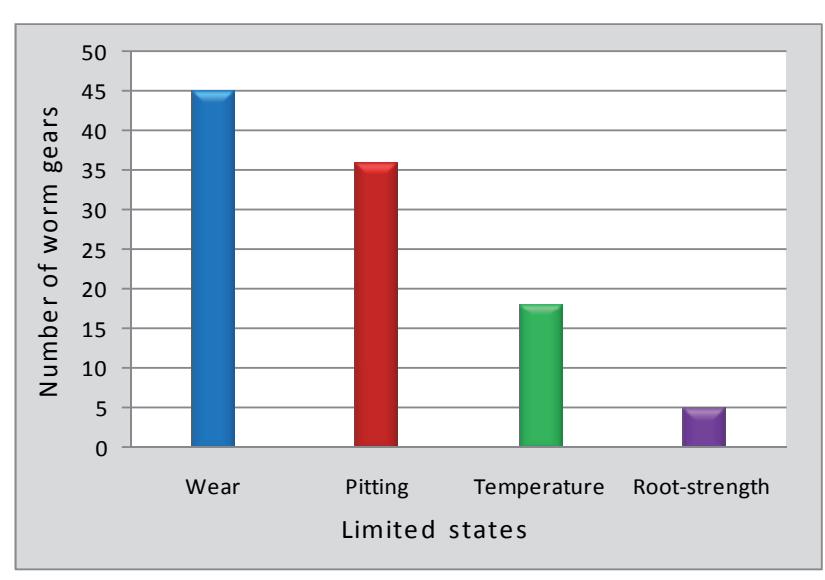

Fig.4. Comparison of boundary conditions of 81 worm gear pairs

From the viewpoint of utilisation of available worm gear transmissions, it is extremely important that worm gear has a similar capacity for all boundary conditions. In the analysis it has been marked as uniform (UN - uniform load capacity), i.e. uneven load capacity (UN - uneven load capacity). Out of 81 gears only 23 gears exhibit uniform load capacity, in 13 gears the load capacity is approximately uniform, while in 45 gears the load capacity is uneven. The best utilisation of available worm gear resources has been obtained in a gear with a tin bronze pinion. 


\section{CONCLUSION}

Based on this display we can draw the following conclusions:

1. The analysis of worm gear load capacity according to the DIN 3996-2012, along with the variations of the crucial construction parameters (transmission ratio, speed, worm gear material, center distance), shows that their capacity is mainly limited as a result of damage due to wear, pitting and increased operating temperature. Out of 81 analysed gears, 45 gears exhibit critical wear, 36 pitting and 18 increased operating temperature.

2. From the viewpoint of utilisation of worm gear available resources, out of 81 analysed gears, 23 gears exhibit uniform load capacity, in 13 gears the load capacity is approximately uniform, while in 45 gears the load capacity is uneven. The best utilisation of available worm gear resources has been obtained in a gear with a tin bronze pinion.

3. The analysis was performed on worm gears which are most widely used. Thus, the obtained results are of significance for engineering practice.

\section{REFERENCES}

[1] DIN 3996 (9/2012). Tragfähigkeitsberechnung von Zylinder-Schneckengetrieben mit sich rechtwinklig kreuzenden Achsen.
[2] Weber, C., Maushake, W. (1956). Untersuchung von Zylinderschneckengetrieben mit rechtwinklig sich kreuzenden Achsen. Verlag Vieweg, Braunschweig.

[3] Predki, W. (1982). Hertzsche Drücke, Schmierspalthöhen und Wirkungsgrade von Schneckengetrieben. Dissertation. Uni. Bochum.

[4] Magyar, B., Sauer, B., Horák, P. (2012). Tribological Investigation of K Type Worm Gear Drives. Acta Polytechnica Hungarica, Vol. 9, No.6. pp. 233-252, ISSN 1785-8860.

[5] Berger, M., Sievers, B., Hermes, J. (2015). Standardized Wear and Temperature Prediction for Worm Gears under Non-Steady Operating Conditions, International Conference Gears. October, 2015, Munich, Germany, VDI Berichte 2255.1 - pp.483-492. VDI-Society for Product and Process Design.

[6] Oehler, M., Magyar, B., Sauer, B. (2015). High efficiency worm gear drives 106, International Conference Gears. October 2015, Munich, Germany, VDI Berichte 2255.2 - pp.937-948. VDI-Society for Product and Process Design.

[7] Miltenović, V., Banić, M., Miltenović, A. (2012). Modern Approach for Load Capacity Calculation of Worm Gears, 7th International symposium Constuction, Shaping, Design - KOD 2012, 24-26 May, Balatonfüred, Hungary, ISBN 978-86-7892399-9, pp. 55 - 64.

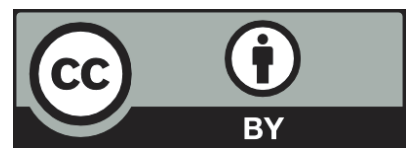

(C) 2017 Authors. Published by the University of Novi Sad, Faculty of Technical Sciences.

This article is an open access article distributed under the terms and conditions of the Creative Commons Attribution license 3.0 Serbia (http://creativecommons.org/licenses/by/3.0/rs/). 